\title{
De frente ou de costas, o teatro*
}

\section{Paulo Eduardo Carvalho}

\author{
Maria Helena Serôdio (coord.), Clara Riso, José Maria Vieira \\ Mendes, Maria João Caetano, Teresa Faria (org.), Teatro \\ em debate(s), Lisboa, Livros Horizonte, 2003, 309 pp.
}

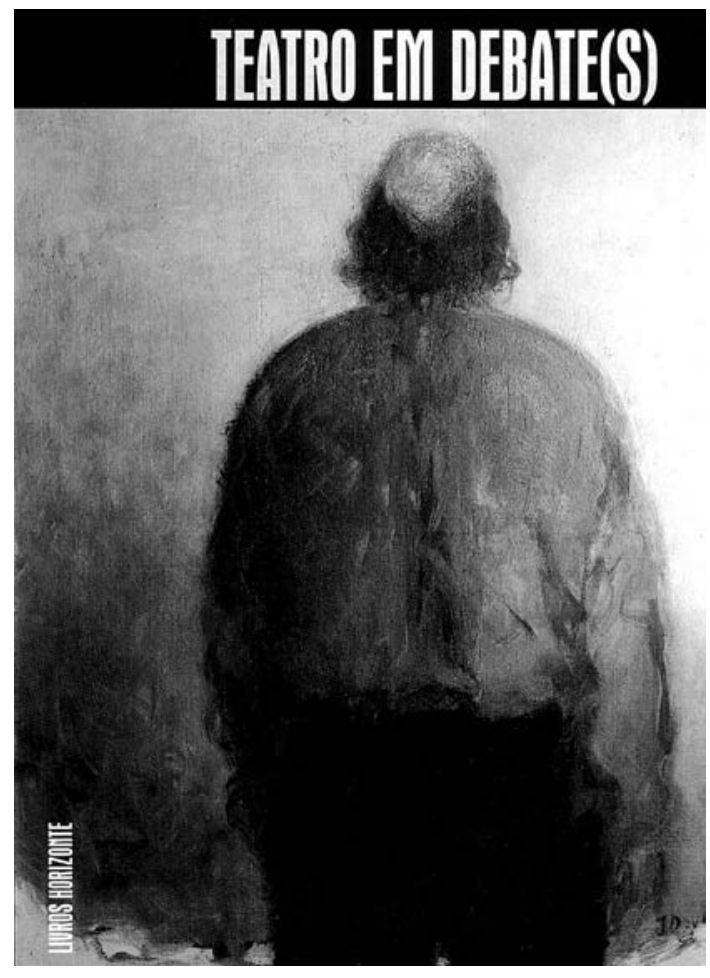

Começo pelo "rosto" duplamente enigmático deste livro: a reprodução de um quadro retratando um homem de costas, encimado por um título que especifica a matéria dominante das suas páginas - o Teatro -, e termina pela abertura à possibilidade de um plural aparentemente redundante - em debate(s). Legítimo será que nos interroguemos se não será todo o debate, entendido como exposição de razões em defesa ou contra uma opinião ou argumento, ou ainda como exame conjunto de um assunto, questão ou problema, um exercicio sempre necessariamente plural e colectivo? Mas esta reflexão perplexa autorizada pelo título surge intensificada, em inquietante contradição, pela aparente imagem de recusa de uma corpulenta figura humana que nos oferece as costas. Nada nesta nossa primeira abordagem a este livro nos esclarece de forma inequívoca sobre as proposições que ocupam as suas generosas mais de 300 páginas. E é só quando partimos em busca do seu "dorso" ou ultrapassamos o enigma desse rosto, folheando as suas primeiras páginas, e deixando os nossos olhos percorrer agora, respectivamente, o texto da contracapa ou o seu
Índice e Prefácio, que sentimos pacificada a referida perplexidade ao ponto de validarmos como produtiva uma tão singular estratégia de convite à leitura. Na realidade, Teatro em debate(s) reúne grande parte do material apresentado em duas iniciativas distintas e afastadas no tempo: o $1^{\circ}$ (e, até agora, único) Congresso do Teatro Português, realizado nas instalações da Fundação Calouste Gulbenkian entre 22 e 24 de Novembro de 1993, por iniciativa de uma expressiva variedade de centros, associações e outras entidades (entre as quais, a Associação Portuguesa de Críticos de Teatro), e o colóquio O Homem de Costas: 0 Corpo no Teatro, Cinema, Fotografia e Artes Plásticas, organizado pelo Centro de Estudos de Teatro, a 8 de Abril de 2002, numa das salas da mesma Fundação.

No desconhecimento ainda do seu conteúdo efectivo, esta informação esclarece-nos imediatamente da estratégia utilizada pelo jogo gráfico contido no título. A leitura das muitas contribuições registadas neste livro, correspondendo aos múltiplos debates ocorridos e agora aqui recuperados, reforça e valida a natureza plural do seu conteúdo. Contudo, tão diversa e heteróclita é a natureza dos muitos testemunhos, estudos e intervenções várias que integram Teatro em debate(s) que justo será sugerir que mais do que plural, este livro é quase um hibrido: não só porque resulta de um produtivo cruzamento de iniciativas com progenitores institucionalmente diversos, mas também porque diversas foram as suas motivações e diversas as contribuições efectivas. (Da consciência de tal hibridismo parece dar-nos conta a subtil mudança de cor do papel em que se reúnem respectivamente os materiais do Congresso do Teatro Português e os do Colóquio 0 Homem de Costas.)

0 "homem de costas" reproduzido na capa é um autoretrato do pintor José David, exactamente a imagem escolhida para aquele colóquio, em Abril de 2002, originalmente pedida de empréstimo à segunda edição da obra de Georges Banu que inspirara aquele encontro: L'homme de dos. Peinture, theâtre (Adam Biro, 2001, p. 258). Mas se o recurso à imagem que marcara a mais recente das iniciativas contempladas pela ambição documental deste livro encontra plena justificação, o mesmo não se poderá tão imediatamente dizer da opção em colocar um "homem de costas" sobre o "rosto" de um objecto que, estou certo, os seus organizadores - isto é, aqueles que, durante largos meses, o "carregaram nas costas": para além de Maria Helena Serôdio, que coordenou, também Clara Riso, José Maria Vieira Mendes, Maria João Caetano e Teresa Faria - quererão que seja lido 
e consultado por todos aqueles que se interessam pela matéria do teatro, do seu fazer actual e da própria história desse fazer. $E_{1}$ contudo, como nos repetem as muitas intervenções dos participantes naquele colóquio aqui reproduzidas, afirma-se como incomparável a atracção, a sedução e a multiplicação de sentidos da postura de costas, nas diferentes artes e manifestações que trabalham com a figuração humana. Em lugar de condenado a uma repetida, e muitas vezes esvaziada, frontalidade, este "homem de costas" desafianos, deste modo, a acompanhar a direcção do seu olhar, mergulhando nas muitas páginas de leitura encerradas neste objecto. E uma vez que este é um livro de teatro, será legítima a ficção de que este convite "distanciado" é também um desafio reforçado a uma leitura crítica e empenhada, em consonância com a própria natureza de muitas das intervenções mais "frontais" que aqui teremos oportunidade de encontrar.

Ultrapassado o esclarecedor Prefácio assinado pela Comissão Editorial, o primeiro e mais frontal documento que nos oferece este livro é um valioso material inédito que se propõe dar-nos conta das "iniciativas diversas, que reuniram ao lado de profissionais de teatro outras presenças em debate aberto sobre questões várias, e de que ficaram publicados documentos, artigos, actas ou comunicações dispersas" (p. 11). Trata-se de um texto escrito propositadamente para este volume por Maria Helena Serôdio, com a "ajuda preciosa" de Teresa Faria, que recenseia e equaciona, com rigor e clareza, iniciativas tão diversas como, entre outras, o Simpósio 0 Texto e o Acto: 32 Anos de Teatro (1968-2000), em 1984, o $1^{\circ}$ Congresso Luso-Espanhol de Teatro, em 1987, o $1^{\circ}$ Encontro Nacional de Teatro, em 1989, ou o $11^{\circ}$ Congresso da Associação Internacional de Críticos de Teatro', em 1990, para além de muitas das revistas de teatro que durante estes anos foram surgindo e desaparecendo, como a Teatruniversitário, a 0 actor, a Palcos ou a Percursos - Cadernos de arte e educação. Só por humilde estratégia é que esta breve história da "Reflexão sobre teatro" em Portugal até 1993 surge modulada como "memórias dispersas": para além de sistematizar esses outros "debates", dando-nos conta das suas principais conclusões ou implicações, este estudo é atravessado pela produtiva ambição de articular as diferentes iniciativas com o seu tempo histórico e as diversas conjunturas políticas, culturais e estéticas que marcaram mais de vinte anos de reflexão sobre teatro em Portugal. Este documento não só cria o contexto indispensável à leitura das actas possíveis do $1^{\circ}$ Congresso do Teatro Português, como alarga consideravelmente o interesse histórico deste volume. Se algum reparo se justifica será só que, para o leitor entusiasmado, muito útil teria sido ver tal estudo completado, cobrindo os dez anos seguintes, a servir, por exemplo, de fronteira entre as referidas actas e o material do Colóquio o Homem de Costas... Uma tarefa, certamente, a completar. Depois de um oportuno apontamento, assinado por Maria João Caetano, sobre as "Expectativas em relação ao Congresso", reflectidas na imprensa portuguesa da altura, seguem-se as actas do Congresso. As primeiras palavras de reconhecimento terão de ir para o incansável trabalho de arqueologia "editorial" que se imagina por detrás destas cerca de 170 páginas, recuperando textos, avaliando a sua pertinência e mais produtiva distribuição, reorganizando as quatro grandes áreas de debate em que o próprio Congresso originalmente se organizara: Criação, Produção, Recepção e Formação. A estruturação e a qualidade argumentativa determinam a importância muito variada das diversas contribuições recuperadas e coligidas, de 33 participantes mais activos (listados no final destas actas). Tal disparidade nem sempre será o melhor convite à leitura, mas, tal como advertira o Prefácio, é inegável o seu "valor documental" (p. 9) e, consequentemente, a pertinência da sua publicação por iniciativa de um Centro de Estudos de Teatro que tem colocado a questão - tão debatida nas próprias páginas destas actas - da documentação teatral entre as suas principais preocupações. Entre o texto de Maria Helena Serôdio já referido, o texto de Joaquim de Carvalho, sobre as conclusões do $1^{\circ}$ Encontro Nacional de Teatro, realizado em 1989, que abre, com total oportunidade, esta colecção, e o texto final, novamente da responsabilidade de Maria Helena Serôdio, esboçando então (em 1993) as "Conclusões aprovadas no final dos trabalhos do Congresso" é toda uma história do teatro português de cerca de vinte anos que se estabelece. Aquilo que se oferece imediatamente como mais produtivo, do ponto de vista da leitura de todas estas intervenções aqui coligidas, no final deste ano de 2003, é não só $a$, infelizmente ainda, mais do que útil identificação de algumas das "disfunções crónicas do teatro em Portugal" (p. 22), mas também a consciência do que eventualmente se possa ter feito no sentido de contrariar, sanar ou ultrapassar circunstâncias difíceis nas quais o pior será sempre ver algum tipo de manifestação atávica, pois essa tende a ser a interpretação escolhida pela preguiça e pela incompetência. Talvez que o mais doloroso diagnóstico que encontramos nestas abundantes páginas seja aquele enunciado por Carlos Porto, ao declarar a "ausência [em Portugal] de vínculos sérios entre o teatro e a sociedade a que pertence" (p. 62)...

Seja como for, num momento em que grande parte das condições de funcionamento do sistema teatral em Portugal volta a ser equacionadas - bastará referir que, em dez anos, do Instituto das Artes Cénicas passámos para o Instituto Português das Artes do Espectáculo e, mais recentemente, para o Instituto das Artes... - muitas das reflexões mais combativas ou inquietas expressas nestas páginas ultrapassam o seu interesse histórico para adquirirem uma desconfortável actualidade. Refiro-me à centralidade que as questões de produção continuam a ocupar na discussão sobre teatro em Portugal. Não obstante os claros esforços desenvolvidos pela organização do $1^{\circ}$ Congresso de Teatro Português, no sentido de equilibrar uma discussão alargada sobre as múltiplas dimensões e valências da experiência teatral, um claro diagnóstico que emerge da leitura destas intervenções é o modo como a fragilidade do sistema produtivo continuava a inibir uma discussão mais aprofundada das questões artísticas e estéticas. 


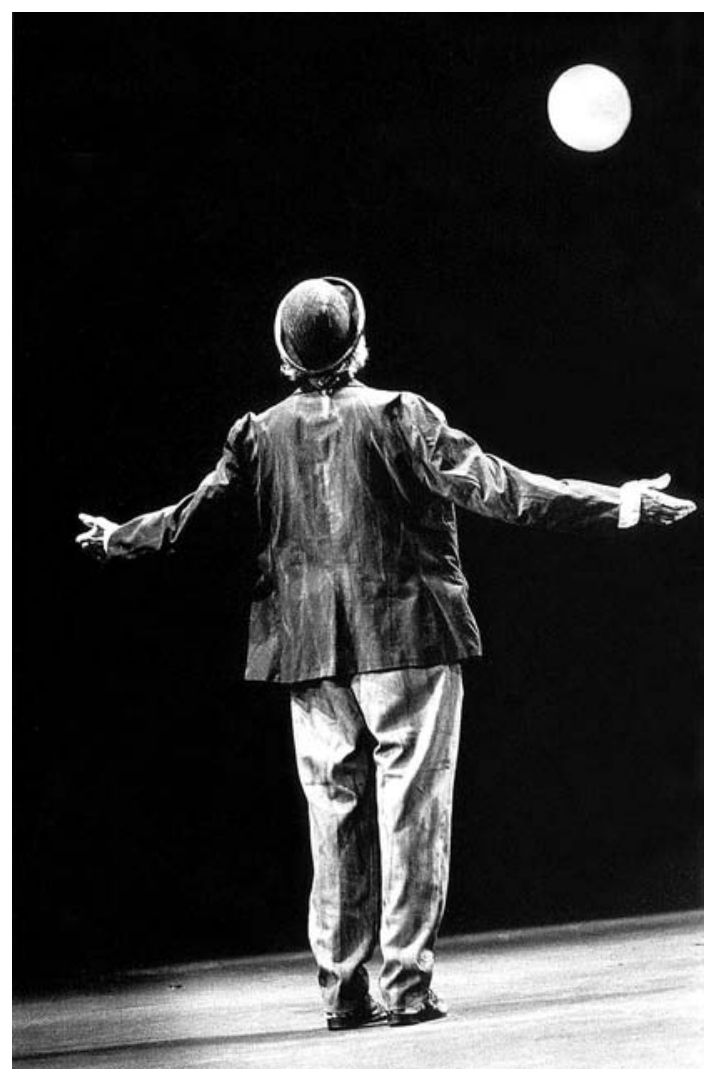

Na impossibilidade de uma referência mais demorada a cada uma das muitas contribuições, arrisca-se a identificação de algumas das questões que as atravessam para que se possa avaliar do seu actual estado de evolução, entre os extremos da paralisia ou da aparente resolução: a questão da dramaturgia portuguesa e do seu espaço no contexto da criação teatral, a ligação dos dramaturgos ao trabalho da cena e a necessidade de mecanismos de estímulo e promoção (Jaime Gralheiro, José Jorge Letria e Prista Monteiro); a articulação entre a televisão e o teatro, seja na realização de trabalhos específicos para aquele meio de expressão, seja no seu papel de registo (Paulo Filipe e Maria Helena Dá Mesquita); o papel da crítica num contexto de retracção, sobretudo a nível da imprensa escrita (Adolfo Gutkin, Carlos Porto e Maria Helena Serôdio); as questões mais variadas da descentralização (Leandro Vale, José Mascarenhas), da necessidade de um sistema elaborado de itinerância e de uma política efectiva de apoio autárquico (José Rui Martins), dos espaços de representação, entre o desaparecimento repetido de salas de teatro (Pedro Pinheiro) e a necessidade de uma rede nacional de teatros, do teatro amador (Jorge Bracourt), da situação do teatro de revista (Helder Freire Costa, Francisco Nicholson), do estatuto do actor (Mário Jacques), dos cuidados a nivel da formação (Né Barros) e da utilidade pedagógica da experiência dramática (Fernando Peixoto, Júlia Lello, Carlos Vieira de Almeida, Júlia Correia).

Algumas contribuições revelam uma exigente lucidez na sistematização de coordenadas actualizadas para o desenvolvimento do teatro português: de algum modo respondendo aos provocatórios "avisos à navegação" que encontramos nas intervenções de André Gago ou Castro Guedes, sobre a necessidade de articular uma legislação adequada com uma atitude renovada por parte de muitas das companhias e estruturas de produção, o texto de Joaquim
Barry McGovern em À espera de Godot enc. Walter Asmus, Gate Theatre, Dublin, 1999, fot. John Haynes.
Benite sobre "Produção e Subsídios" enumera com singular lucidez as "condições prévias" à criação teatral portuguesa, assentes na "formação técnica e artística específica,

equipamentos necessários e uma estrutura burocrática que enquadre e organize esta actividade através da programação, comercialização e administração" (p. 117), colocando assim um peso significativo na "gestão" e na "produção", domínio que outro participante, Varela Silva, apontava, então, como "o mais desactualizado elemento no espectáculo" português (p. 122). Um último núcleo de contribuições inclui verdadeiros estudos, sejam sobre os espaços teatrais setecentistas (Maria Alexandra Trindade Gago da Câmara), o teatro musical de Constança Capdeville (Maria João Serrão) ou o teatro de Natália Correia (Júlia Lello), e até mesmo estimulantes testemunhos sobre a prática criativa, como aquele do Teatro da Garagem sobre os "aspectos criativos do trabalho cenográfico desenvolvido ao longo dos [primeiros] quatro anos de actividade" da companhia (p. 91).

No texto "Uma paixão estética para a crítica", apresentado nesse Congresso de 1993, Maria Helena Serôdio começa por comentar o modo como "a crítica se tem vindo a confrontar com a progressiva complexificação da criação teatral à qual procura responder com aprendizagens várias e exercícios diferentes", para depois acrescentar:

Refiro-me, no campo da crítica, aos saberes e procedimentos da semiologia, da antropologia e da sociologia, bem como ao conhecimento de outras disciplinas artisticas, como a pintura, a música, a dança ou a literatura e, claro, ao prolongamento do exercício crítico pelo ensaio e pela mais alargada investigação no domínio dos Estudos de Teatro; no campo do teatro, refiro-me à sua deriva deliberada por outras artes a exigirem procedimentos heuristicos mais elaborados, à multiplicação de iniciativas, à procura da diferença na expressão da inquietude contemporânea, às novas modulações da voz, do corpo e da visibilidade a reconstruírem o nosso imaginário em constelações performativas. (p. 165) 


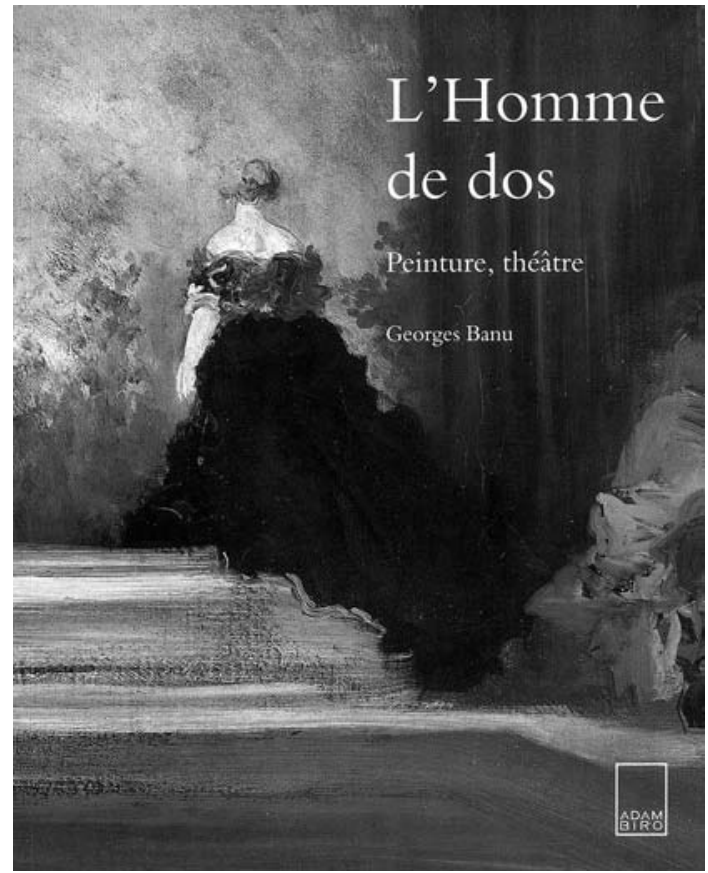

Servem estas palavras para apresentar os materiais que ocupam a segunda parte deste livro, correspondentes ao Colóquio 0 Homem de Costas: 0 Corpo no Teatro, Cinema, Fotografia e Artes Plásticas, uma iniciativa que, tendo tomado como motivação a já referida e inspirada obra de Georges Banu, anuncia, no cruzamento de olhares que propõe (e que ultrapassam aqueles trabalhados pelo próprio teatrólogo francês), um efectivo alargamento do campo de reflexão dos Estudos de Teatro entre nós.

Retomo o olhar inquiridor sobre o "homem de costas" que se apresenta na capa deste livro, com a citação dos dois parágrafos de abertura do texto de Georges Banu, reproduzido, neste volume, infelizmente, na mesma lingua em que o autor o escreveu e apresentou entre nós, pelo que arrisco uma tradução possivel, com o ambicioso, mas legítimo, propósito de chegar a um mais alargado público leitor:

0 homem de costas repousa do olhar. Aos olhos que o perscrutam, aos rostos que o chamam, às pupilas que o interrogam, na luz dos museus ou na noite dos teatros, sucede o silêncio enigmático, e as mais das vezes provisório, das costas. Deste modo, duas solidões em co-presença, actor e público, deixam de buscar o contacto directo e a "apóstrofe muda" que todo o olhar (...) lança na direcção do espectador dá, temporariamente, lugar à suspensão do apelo. Reticente ao diálogo, o homem de costas só se pode instaurar por defeito, confrontado com o desejo de comunicação que o face-a-face cultiva.

Virar as costas implica sempre uma recusa... e em cada ocasião caberá sempre ao espectador explorar o segredo do homem de costas. Ignorando-nos, que afirma ele? De que foge ele? Que busca ele? Ou, até mesmo, porque se demora ele a um tal ponto no exercicio do seu labor? Tantas mais perguntas, quando a evidência dos olhares e a clareza dos rostos são sacrificados em beneficio das costas, às quais tais atributos são estranhos. As costas afirmam, pelo contrário, a força enigmática de um corpo presente que intriga o espectador na medida em que este perdeu a sua habitual posição de parceiro privilegiado, uma vez que, estranho a qualquer efeito de representação, o homem de costas trabalha, espera ou afasta-se. E assim a evidência de uma identidade individual esbate-se em beneficio de uma actividade concreta ou da pertença a um grupo. Se o homem sem rosto é o homem sem nome, ele não é, apesar disso, o homem sem acto. (p. 213)
Estas considerações introdutórias de Georges Banu não só esclarecem melhor o funcionamento comunicativo da capa deste volume e do disseminado labor colectivo que ele teve por detrás para a sua concretização, como ilustram de forma eloquente o mote em torno do qual se organizaram as intervenções neste colóquio, entre alocuções mais demoradas, de especialistas representativos de diversas práticas e saberes, e dois painéis que contaram com contribuições mais breves, mas nem por isso menos valiosas. Os textos de maior folgo, diversamente concentrados na questão da posição de costas e das suas implicações metafóricas ou tão simplesmente na questão do corpo permitida pelo subtítulo do colóquio, demonstram uma mais tranquila reflexão sobre o temário proposto. Leiamse os, ora mais informativos, ora mais reveladores, trabalhos de Luiz Francisco Rebello, sobre a postura de costas na história do teatro, de Ana Gabriela Macedo, sobre as múltiplas valências da iconografia feminina na pintura de Paula Rego (convocando para o efeito ampla reflexão no domínio dos Cultural Studies), de João Mário Grilo, numa surpreendente inversão do problema aplicado ao cinema, reequacionando o papel e o corpo do espectador, de Fernando Guerreiro, com um exercício quase poético sobre uma pletora de objectos e experiências cinematográficas, e de André Barata, com uma exigente reflexão sobre o "detrás" na nossa experiência do mundo.

Embora igualmente abertos ao estudo de determinados casos e situações, os dois painéis apostaram sobretudo no testemunho de criativos ligados às diversas práticas artisticas convocadas, com uma assumida preferência reconhecida ao teatro. 0 que estas páginas agora registam foi aquilo que encenadores (João Brites e João Lourenço), críticos e investigadores (Carlos Porto, Rui Cintra e eu próprio), um actor (João Pedro Vaz), um cineasta (Pedro Sena Nunes), uma coreógrafa (Madalena Victorino) e uma fotógrafa (Susana Paiva), foram levados a pensar, num raro exercício de auto-reflexividade, sobre a problemática da perspectiva de costas, no domínio da sua experiência. Ultrapassada a surpresa ou perplexidade face ao desafio proposto, manifestada pela generalidade dos participantes, aquilo 


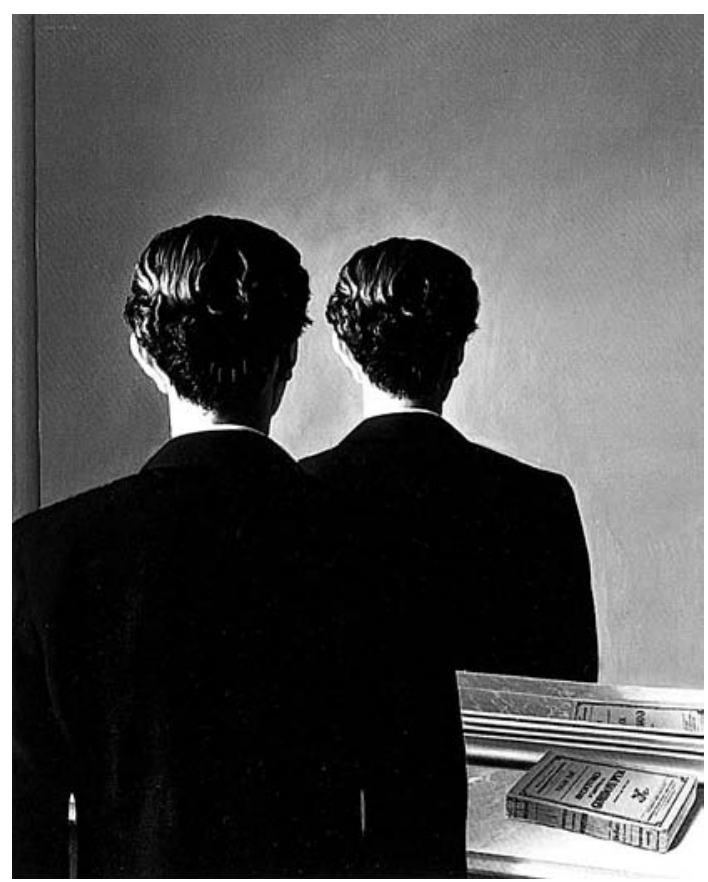

que agora aqui encontramos são reflexões diversas sobre a ampla eloquência do corpo em variadas formas de expressão. João Brites acrescenta mais um testemunho sobre a poética cénica que há décadas vem explorando, recuperando a sua própria experiência no "desenvolvimento das relações dialécticas entre o que é expresso, explicita ou implicitamente, pela palavra e o que é expresso, explicita ou implicitamente, pelo corpo" (p. 253). João Lourenço, além de referir alguns dos espectáculos também por si encenados, oferece-nos um documento rico e comovente sobre a própria memória do teatro português dos últimos mais de quarenta anos, convocando a sua inicial experiência de actor, num tempo em que o teatro portuquês era ainda dominado por "ensaiadores": pelo seu texto passam as memórias da estreia, entre nós, de A morte do caixeiro viajante, de Arthur Miller, na encenação de António Pedro, mas também o Ȧ espera de Godot, de Samuel Beckett, em 1959, na encenação de Ribeirinho, "a primeira pequena revolução numa sala de teatro", em Portugal (p. 259).

(Justamente uma das peças convocadas por Georges Banu, no seu livro, a propósito dos quadros de Caspar David Friedrich.)

Rui Cintra alinha algumas notas sobre o lugar do corpo em algumas das manifestações mais recentes do teatro português. Eu próprio arrisco a leitura de um espectáculo de Ricardo Pais, A salvação de Veneza, na perspectiva do uso das posturas de costas. Madalena Victorino explora o movimento da torsão e o desafio do caminhar de costas. João Pedro Vaz convoca a sua própria experiência de comunicação física com o espectador. Susana Paiva reflecte sobre as modalidades do exercício da fotografia em Portugal. E Pedro Sena Nunes, sobre a sua dupla experiência de cineasta e espectador.

A sugestão inicial do "hibridismo", convocada para descrever este volume, serve também para sublinhar como a extraordinária pluralidade de contribuições que habita estas páginas corresponde à própria condição epistemológica dos Estudos do Teatro, interdisciplina condenada - para além das oscilações de paradigma que, como qualquer campo de saber, vem conhecendo - a uma
René Magritte,

La Reproduction interdite (retrato de Edward James), óleo sobre tela, 1937. instabilidade de fronteiras, naquilo que faz tanto a sua dificuldade como a sua riqueza. Enquanto vamos enfrentando, caso a caso, as dificuldades na escolha da disciplina mais adequada para estudar o objecto teatral, nas suas diferentes valências de forma de representação cultural, meio de expressão ou forma artística, resta-nos a atenção redobrada a todas as disciplinas que possam servir para o iluminar. Só da intensificação de um olhar prismático sobre o teatro poderá resultar idêntico apuramento dos nossos instrumentos e do nosso conhecimento e, por isso, o valor da interdisciplinaridade será medido pela riqueza trazida por tal confronto ao debate crítico. Ao sublinhar o duplo interesse documental e reflexivo deste volume de Teatro em debate(s), importa reconhecer a sua complexa inscrição histórica, oferecendose firme no dorso no presente, com um olhar inquiridor voltado sobre o passado e um outro olhar mais exigente lançado para o futuro. Porque, como nos recorda Georges Banu, "as costas são um convite a olhar mais longe, para além da evidência de um sentido ou do esplendor de um rosto".

* Este texto recupera a apresentação pública de Teatro em debate(s), realizada no dia 24 de Novembro de 2003, às 18h00, na Faculdade de Letras de Lisboa. 